\title{
JURNAL EKONOMI \\ EFEKTIF

\section{PENGARUH KOMPENSASI, MOTIVASI DAN DISPLIN TERHADAP KINERJA KARYAWAN PADA PT SUNINDO ADI PERSADA}

\author{
Yan Kristian Halomoan \\ halo.krist@gmail.com
}

\begin{abstract}
ABSTRAK
Tujuan penelitian ini adalah untuk mengetahui pengaruh pengaruh kompensasi, motivasi dan displin terhadap kinerja karyawan pada PT Sunindo Adi Persada

Metode yang digunakan adalah metode deskriptif kuantitatif Populasi sebanyak 439orang, teknik sampling yang digunakan adalah proporsional random sampling menggunakan metode teknik sampling menggunakan rumus Slovin tingkat galat 5\% didapat 209 responden. Analisis data menggunakan analisis regresi, analisis koefisien korelasi, analisis koefisien determinasi dan uji hipotesis.

Berdasarkan hasil penelitian kompensasi ( X1 ), Motivasi ( X2 ) dan Disiplin ( X3 ) secara bersama-sama berpengaruh positif dan signifikan terhadap Kinerja pada karyawan ( Y ) PT. Sunindo Adi Persada. Hal ini dapat dibuktikan dari nilai regresi berganda yang diperoleh yaitu $\mathrm{Y}=7,887+0.294 \mathrm{X} 1+0.368 \mathrm{X} 2+0,233 \mathrm{X} 3$, Nilai $\mathrm{F}$ hitung $100,144>\mathrm{F}$ tabel 2,41 dengan siginifikan $0,000<0,05$, besarnya kontribusi Kompensasi (X1) Motivasi (X2) dan Disiplin (X3) terhadap variabel kinerja karyawan (Y) sebesar 58,8\%.
\end{abstract}

\section{Kata Kunci: Kompetensi, Motivasi, Disiplin, Kinerja}

\section{ABSTRACT}

The purpose of this study was to determine the effect of competence, career development and work environment on employee job satisfaction at PT. Boga Lestari Sentosa Indonesia (Kenny Rogers Roasters)

The method used is descriptive method with an associative approach. A population of 219 people, the sampling technique used was proportional random sampling using a sampling technique using the Slovin formula with a sample of 69 respondents. Data analysis using regression analysis, correlation coefficient analysis, coefficient of determination analysis and hypothesis testing.

Based on the results of competency research (X1) career development (X2) and work environment (X3) have a positive and significant effect on employee job satisfaction (Y) with a regression equation $Y=6.547+0.245 X 1+0.263 X 2+0.338 X 3$. Correlation coefficient value obtained at 0.732 means that the independent variable with the dependent variable has a strong influence with the coefficient of determination or influence simultaneously at $53.6 \%$ while the remaining $46.4 \%$ is influenced by other factors. Hypothesis testing obtained by calculating the value of $F>F$ table or $(25.068>2.510)$, this is also strengthened by a probability of significance of $0,000<0.05$. Thus $\mathrm{HO}$ is rejected and $\mathrm{H} 4$ is accepted. This means that there are 
positive and significant simultaneous influences between competence, career development and work environment on employee job satisfaction.

\section{Keywords: Competence, Career Development, Work Environment, Job Satisfaction}

\section{PENDAHULUAN}

\section{A. Latar Belakang Masalah}

Sumber daya manusia inilah yang menjalankan kegiatan sehari-hari. Karyawan merupakan living organisme memungkinkan berfungsinya suatu organisasi atau perusahaan dan menjadi unsur penting dalam manajemen. Agar pekerja dapat melaksanakan tugasnya dengan baik, maka di dalam perusahaan diciptakan sistem manajemen yang dikenal dengan manajemen karyawan.

Selama periode lima tahun hasil produksi unit boneka pada PT. Sunindo Adi Persada mengalami peningkatan pada tahun 2012 sebesar 5.12\%, namun Pada tahun 2013 jumlah unit hasil produksi mengalami penurunan sebesar $6.67 \%$, kemudian pada tahun 2014 jumlah unit hasil produksi juga mengalami penurunan sebesar $4.66 \%$, pada tahun 2015 jumlah unit hasil produksi kembali mengalami penurunan sebesar $12.42 \%$ dan pada tahun 2016 jumlah unit hasil produksi kembali lagi mengalami penurunan sebesar $16.34 \%$. dalam hal ini menunjukan bahwa secara data kuantitas hasil produksi yang dihasilkan oleh karyawan PT. Sunindo Adi Persada mengalami penurunan, penurunan unit hasil produksi boneka disebabkan oleh salah satu faktor yaitu pemberian kompensasi berupa gaji yang belum sesuai dengan penerapan undang undang tenaga kerja no.13 tahun 2003 Pasal 90 sehingga berdampak kinerja pada karyawan PT Sunindo Adi Persada semakin menurun.

Proses motivasi sangat tergantung pada kemampuan pemimpin untuk mempengaruhi bawahannya dalam upaya mewujudkan tujuan organisasi. Keberhasilan atau kegagalan yang dialami sebagian besar organisasi ditentukan oleh kualitas kepemimpinan yang dimiliki oleh orang-orang yang diberikan tugas untuk memimpin organisasi tersebut, terjadi peningkatan jumlah karyawan yang ijin, terlambat dan tidak hadir kerja tiap tahunnya. Pada tahun 2012 jumlahnya sebanyak 97 orang, Pada tahun 2013 jumlahnya sebanyak 102 orang, Pada tahun 2014 jumlahnya sebanyak 106 orang, Pada tahun 2015 jumlahnya sebanyak 111 orang, Pada tahun 2016 jumlahnya114 orang,

Berdasarkan hasil data yang diperoleh bahwa penurunan unit hasil produksi boneka juga disebabkan oleh kurangnya motivasi yang diberikan kepada karyawan sehingga berdampak kinerja pada karyawan PT Sunindo Adi Persada semakin menurun.

Dengan demikian, karyawan dapat melaksanakan tugasnya dengan penuh kesadaran serta dapat mengembangkan tenaga dan pikirannya semaksimal mungkin demi terwujudnya tujuan organisasi. Jika lingkungan kerja semuanya disiplin, maka seorang karyawan akan ikut disiplin, Tetapi jika lingkungan kerja organisasi tidak disiplin, maka seorang pegawai juga akan ikut tidak disiplin. Untuk itu sangat sulit bagi lingkungan kerja yang tidak disiplin mempengaruhi kedisiplinan karyawan, karena lingkungan kerja akan menjadi teladan bagi para karyawan, disiplin kerja karyawan PT Sunindo Adi Persada masih belum maksimal dalam hal ketepatan waktu, hal ini dapat menimbulkan dampak negatif pada perusahaan sehingga mengakibatkan kegiatan perusahaan menjadi terhambat.

Berdasarkan uraian latar belakang masalah diatas maka penulis menyimpulkan bahawa pemberian Kompensasi yang sesuai, Motivasi yang baik dan peningkatan Disiplin dapat mempengaruhi kinerja karyawan untuk lebih baik lagi sesuai dengan apa yang diharapkan oleh pimpinan perusahaan. Oleh karena itu peneliti sangat tertarik sekali untuk melakukan 
penelitian dengan mengambil judul "Pengaruh Kompensasi, Motivasi Dan Displin Terhadap Kinerja Karyawan Pada Pt Sunindo Adi Persada".

\section{B. Identifikasi Masalah}

1. Belum tercapainya target Produksi yang telah ditentukan oleh perusahaan

2. Belum tercapainya kualitas hasil produksi.

3. Pemberian gaji yang belum sesuai dengan upah minimum regional.

4. Pemberian insentif yang belum tepat.

5. Kurangnya penghargaan dari pimpinan.

6. Kurang memberikan kesempatan kepada karyawan yang berpotensi dalam pengembangan karyawan.

7. Pemimpin belum dapat dijadikan teladan terhadap karyawan.

8. Kurangnya ketegasan pimpinan terhadap karyawan.

\section{Perumusan Masalah}

1. Apakah kompensasi berpengaruh positif dan signifikan terhadap kinerja karyawan pada PT Sunindo Adi Persada?

2. Apakah motivasi berpengaruh positif dan signifikan terhadap kinerja karyawan pad PT Sunindo Adi Persada?

3. Apakah disiplin berpengaruh positif dan signifikan terhadap kinerja karyawan pada PT Sunindo Adi Persada?

4. Apakah kompensasi, motivasi dan disiplin secara simultan berpengaruh positif dan signifikan terhadap kinerja karyawan pada PT. Sunindo Adi Persada?

\section{TINJAUAN PUSTAKA}

\section{A. Kompensasi}

Pada dasarnya manusia bekerja ingin memperoleh uang untuk memenuhi kebutuhan hidupnya. Untuk itu seorang karyawan mulai menghargai kerja keras dan semakin menunjukkan loyalitas terhadap perusahaan dan karena itulah perusahaan memberikan penghargaan terhadap prestasi kerja karyawan yaitu dengan jalan memberikan kompensasi. Kompensasi merupakan kontra prestasi terhadap penggunaan tenaga atau jasa yang telah diberikan oleh tenaga kerja. Kompensasi juga merupakan paket yang ditawarkan organisasi kepada pekerja sebagai imbalan atas penggunaan tenaga kerjanya.

Kebijakan kompensasi merupakan kebijakan yang penting dan strategis karena hal ini langsung berhubungan dengan peningkatan motivasi dan kinerja karyawan dalam suatu perusahaan. Bila perumusan kebijakan kompensasi tepat baik dalam aspek keadilan maupun kelayakannya maka karyawan akan merasa puas dan termotivasi untuk melaksanakan berbagai kegiatan yang berhubungan dengan pencapaian tujuan perusahaan. Sebaliknya bila rasa keadilan dan kelayakan tidak terpenuhi akan menyebabkan karyawan mengeluh, timbul ketidk puasan kerja yang berdampak pada kemerosotan motivasi motivasi kerja karyawan yang pada gilirannya menyebabkan kinerja karyawan akan merosot pula.

Berikut ini disampaikan beberapa pengertian kompensasi menurut beberapa tokoh yaitu:

Menurut Hasibuan (2012: 118), Kompensasi adalah semua pendapatan yang berbentuk uang, barang langsung atau tidak langsung yang diterima karyawan sebagai imbalan atas jasa yang diberikan kepada perusahaan.

Werher dan davis dalam Wibowo (2012:348) mendefinisikan kompensasi adalah sebagai apa yang diterima pekerja sebagai takaran atas kontribusinya kepada organisasi.

Dessler (2010:85) kompensasi karyawan adalah setiap bentuk pembayaran atau imbalan yang diberikan kepada karyawan dan timbul dari diperkerjakannya karyawan itu. Kompensasi 
berbentuk pada semua bentuk upah atau imbalan yang berlaku bagi dan muncul dan pekerjaan. Kompensasi finansial langsung terdiri dari gaji dan insentif. Adapun kompensasi finansial tidak langsung dapat berupa berbagai macam fasilitas dan tunjangan. Adapun kompensasi non finansial dapat berupa pekerjaan dan lingkungan pekerjaan.

Werther dan Davis (2010) menyatakan bahwa kompensasi merupakan sesuatu yang diterima pegawai sebagai penukar atas kontribusi jasa mereka bagi organisasi. Jika dikelola dengan baik, maka kompensasi membantu organisasi mencapai tujuan dan memperoleh, memelihara, dan menjaga pegawai dengan baik. Sebaliknya tanpa kompensasi yang memadai, maka pegawai yang ada saat ini sangat mungkin akan meninggalkan organisasi, dan organisasi akan kesulitan untuk merekrut kembali pegawai yang sesuai dengan kebutuhan.

Mathias dan Jackson (2011) menekankan bahwa pada dasarnya manusia bekerja juga ingin memperoleh uang untuk memenuhi kebutuhan hidupnya. Untuk itulah seorang karyawan mulai menghargai kerja keras dan semakin menunjukkan loyalitas terhadap perusahaan dan karena itulah perusahaan memberikan penghargaan terhadap prestasi kerja karyawan yaitu dengan jalan memberikan kompensasi. Salah satu cara manajemen untuk meningkatkan prestasi kerja, memotivasi dan meningkatkan kinerja para karyawan adalah melalui kompensasi

\section{B. Motivasi}

Muchdarsyah (2011:205). mengatakan bahwa "motivasi adalah keadaan kejiwaan dan sikap mental yang memberikan energy dan dorongan kejiwaan atau gerakan dan mengarahkan atau menyalurkan perilaku kearah mencapai kebutuhan yang memberikan kepuasan atau mengurangi ketidak seimbangan".

Menurut Rifai (2011:455) "motivasi adalah serangkaian sikap dan nilai-nilai yang mempengaruhi individu untuk mencapai hal yang spesifik sesuai dengan tujuan individu. Sikap dan nilai tersebut merupakan sesuatu kekuatan yang mampu mendorong individu untiuk bertingkah laku mencapai tujuan".

Menurut Effendy (2011:142) "Motivasi adalah kegiatan yang memberikan dorongan kepada seseorang atau dari diri sendiri yang dikehendaki. Jadi dapat dikatakan motivasi bearti motiv, daya gerak atau mengambil keputusan".

Menurut Silalahi (2010:341) "Motivasi juga dapat didefinisikan sebagai dorongan dari dalam diri individu berdasarkan mana dari berperilaku dengan cara tertentu untuk memenuhi keinginan dan kebutuhannya". Adapun pemotivasian dapat diartikan sebagai pemberian motifmotif sebagai pendorong agar orang bertindak, berusaha untuk mencapai tujuan organisasi.

Winardi (2010:1) menjelaskan istilah motivasi (motivation) berasal dari perkataan bahasa Latin, yakni movere yang berarti menggerakkan (to move). Diserap dalam bahasa Inggris menjadi motivation berarti pemberian motif, penimbulan motif atau hal yang menimbulkan dorongan atau keadaan yang menimbulkan dorongan.

Dari beberapa pendapat para ahli diatas maka Motivasi dapat dijelaskan sebagai pemberi daya penggerak yang dapat menciptakan kegairahan dan membangkitkan semangat kerja seseorang untuk melakukan suatu tindakan atau perbuatan agar mau bekerja sama untuk mencapai tujuan yang telah ditetapkan sebelumnya.

\section{Disiplin}

Disiplin kerja menurut Mangkuprawira (2010:19) adalah "sifat seorang karyawan yang secara sadar, mematuhi aturan, dan peraturan organisasi tertentu". Hal itu sangat mempengaruhi kinerja karyawan dan perusahaan. Kedisiplinan sepatutnya dipandang sebagai bentuk latihan bagi karyawan dalam melaksanakan aturan-aturan perusahaan. 
Menurut Hasibuan (2012:193) berpendapat bahwa "disiplin kerja adalah kesadaran dan kesediaan seseorang menaati semua peraturan perusahaan dan norma-norma sosial yang berlaku". Kedisiplinan harus ditegakkan dalam suatu organisasi perusahaan. Tanpa dukungan disiplin karyawan yang baik, sulit bagi perusahaan untuk mewujudkan tujuannya. Jadi, kedisiplinan adalah kunci keberhasilan suatu perusahaan dalam mencapai tujuannya."

Sinungan (2010:146) menjelaskan "Disiplin kerja sebagai suatu sikap mental yang tercermin dalam perbuatan atau tingkah laku perorangan, kelompok atau masyarakat berupa kepatuhan atau ketaatan (obedience) terhadap peraturan-peraturan yang ditetapkan baik oleh pemerintah atau etik, norma, dan kaidah yang berlaku dalam masyarakat untuk tujuan tertentu".

Menurut Mangkunegara (2011:129) "kedisiplinan dapat diartikan sebagai pelaksanaan manajemen untuk memperteguh pedoman-pedoman organisasi"

Menurut Handoko (2010:308) "kedisiplinan adalah kegiatan untuk menjalankan standarstandar organisasi”.

Dari beberapa definisi diatas dapat disimpulkan bahwa disiplin kerja adalah suatu bentuk pelatihan yang berusaha memperbaiki dan membentuk pengetahuan, sikap dan perilaku pegawai sehingga para pegawai tersebut secara sukarela berusaha bekerja secara kooperatif dengan pegawai yang lainnya.

\section{Kinerja}

Menurut Wibowo (2011: 54) kinerja dilihat dari hal kecepatan, kualitas, layanan dan nilai maksudnya kecepatan dalam proses kerja yang memiliki kualitas yang terandalkan dan layanan yang baik dan memiliki nilai merupakan hal yang dilihat dari tercapainya kinerja atau tidak.

Menurut Costello dalam Wibowo (2011: 11) bahwa kinerja adalah gambaran mengenai tingkat pencapaian pelaksanaan suatu kegiatan/program, kebijakan dalam mewujudkan sasaran, tujuan, visi dan misi organisasi yang tertuang dalam strategic planning suatu organisasi.

Menurut Mangkunegara (2010:9) Kinerja karyawan (prestasi kerja) adalah hasil kerja secara kualitas dan kuantitas yang dicapai oleh seseorang pegawai dalam melaksanakan tugasnya sesuai dengan tanggung jawab yang diberikan kepadanya.

Tingkat keberhasilan suatu kinerja meliputi aspek kuantitatif dan kualitatif. Sedangkan, menurut Siswanto (dalam Muhammad Sandy, 2015:11) kinerja ialah prestasi yang dicapai oleh seseorang dalam melaksanakan tugas dan pekerjaan yang diberikan kepadanya. Menurut Simamora (2010:327), kinerja karyawan adalah tingkat terhadap mana para karyawan mencapai persyaratan-persyaratan pekerjaan.

Rivai (dalam Muhammad Sandy, 2015:12) memberikan pengertian bahwa kinerja atau prestasi kerja adalah hasil atau tingkat keberhasilan seseorang secara keseluruhan selama periode tertentu di dalam melaksanakan tugas dibandingkan dengan berbagai kemungkinan, seperti standar hasil kerja, target atau sasaran atau kriteria yang telah ditentukan terlebih dahulu dan disepakati bersama.

Menurut Bangun (2012:213) "kinerja karyawan adalah hasil pekerjaan yang dicapai seseorang berdasarkan persyaratan-persyaratan pekerjaan (Job Requirement), suatu pekerjaan mempunyai persyaratan tertentu untuk dapat dilakukan dalam mencapai tujuan yang disebut juga standar pekerjaan.

Menurut Suwanto dan Priansa (2011:196) Kinerja merupakan performance atau unjuk kerja dan kinerja dapat pula diartikan sebagai prestasi kerja atau pelaksanaan kerja atau hasil unjuk kerja. August W. Smith menyatakan bahwa "performance is output derives from proceses, human otherwise'. Kinerja merupaka hasil dari suatu proses yang dilakukan manusia. 
Dari beberapa definisi diatas dapat disimpulkan bahwa kinerja karyawan adalah prestasi kerja, atau hasil kerja (Out Put) baik kualitas maupun kuantitas yang dicapai karyawan per satuan periode waktu dalam melaksanakan tugas kerjanya sesuai dengan tanggung jawab yang diberikan kepadanya.

\section{METODE PENELITIAN}

Penelitian ini dilaksanakan pada karyawan PT. Sunindo Adi Persada, Jl. Raya Cileungsi $\mathrm{km}$ 22.3, Populasi dari penelitian ini adalah karyawan PT. Sunindo Adi Persada yang berjumlah 439 orang.

Dalam hal ini, peneliti melakukan penarikan jumlah sampel penelitian dengan cara simple random sampling (sampling acak sederhana) dimana sampel dipilih secara acak dari jumlah yang telah ditentukan. Dalam penentuan jumlah sampel tersebut, peneliti menggunakan rumus perhitungan Slovin sebagai berikut :

$$
n=\frac{N}{1+\left(N \cdot e^{2}\right)}
$$

Dimana :

$\mathrm{n}=$ Ukuran sampel

$\mathrm{N}=$ Populasi

$\mathrm{e}=$ Batas toleransi kesalahan (error tolerance 5\%)

Dalam menentukan jumlah sampel yang akan dipilih, penulis menggunakan tingkat kesalahan sebesar 5\%, karena dalam setiap penelitian tidak mungkin hasilnya sempurna $100 \%$, semakin kecil toleransi kesalahan, semakin akurat sampel yang menggambarkan populasi. Jadi sempel dalam penelitian ini berjumlah sebanyak 209 orang yang di ambil dari PT. Sunindo Adi Persada.

Metode Pengumpulan Data menggunkan data primer dan data sekunder, serta uji statistik meliputi, persamaan regresi linear berganda, uji koefisien korelasi, uji deteminsi dan uji hipotesis

\section{HASIL PENELITIAN DAN PEMBAHASAN \\ 1. Uji Kualitas Data}

\section{a. Uji Validitas}

Tabel 4.1 Data Uji Validitas

\begin{tabular}{|c|c|c|c|c|}
\hline Variabel & Indikator & r Tabel & $\begin{array}{c}\text { Corrected item } \\
\text { correlation sampel }\end{array}$ & Keterangan \\
\hline & 1 & 0.138 & 0.417 & Valid \\
& 2 & 0.138 & 0.456 & Valid \\
& 3 & 0.138 & 0.645 & Valid \\
& 4 & 0.138 & 0.638 & Valid \\
Kompensasi (X1) & 5 & 0.138 & 0.712 & Valid \\
& 6 & 0.138 & 0.654 & Valid \\
& 7 & 0.138 & 0.635 & Valid \\
& 9 & 0.138 & 0.657 & Valid \\
& 10 & 0.138 & 0.702 & Valid \\
\hline
\end{tabular}




\begin{tabular}{|c|c|c|c|c|}
\hline Motivasi (X2) & $\begin{array}{c}1 \\
2 \\
3 \\
4 \\
5 \\
6 \\
7 \\
8 \\
9 \\
10\end{array}$ & $\begin{array}{l}0.138 \\
0.138 \\
0.138 \\
0.138 \\
0.138 \\
0.138 \\
0.138 \\
0.138 \\
0.138 \\
0.138\end{array}$ & $\begin{array}{l}0.230 \\
0.362 \\
0.636 \\
0.729 \\
0.691 \\
0.675 \\
0.712 \\
0.716 \\
0.715 \\
0.689 \\
\end{array}$ & $\begin{array}{l}\text { Valid } \\
\text { Valid } \\
\text { Valid } \\
\text { Valid } \\
\text { Valid } \\
\text { Valid } \\
\text { Valid } \\
\text { Valid } \\
\text { Valid } \\
\text { Valid }\end{array}$ \\
\hline Disiplin (X3) & $\begin{array}{c}1 \\
2 \\
3 \\
4 \\
5 \\
6 \\
7 \\
8 \\
9 \\
10\end{array}$ & $\begin{array}{l}0.138 \\
0.138 \\
0.138 \\
0.138 \\
0.138 \\
0.138 \\
0.138 \\
0.138 \\
0.138 \\
0.138\end{array}$ & $\begin{array}{l}0.500 \\
0.565 \\
0.608 \\
0.596 \\
0.651 \\
0.668 \\
0.537 \\
0.730 \\
0.667 \\
0.560\end{array}$ & $\begin{array}{l}\text { Valid } \\
\text { Valid } \\
\text { Valid } \\
\text { Valid } \\
\text { Valid } \\
\text { Valid } \\
\text { Valid } \\
\text { Valid } \\
\text { Valid } \\
\text { Valid }\end{array}$ \\
\hline Kinerja (Y) & $\begin{array}{c}1 \\
2 \\
3 \\
4 \\
5 \\
6 \\
7 \\
8 \\
9 \\
10\end{array}$ & $\begin{array}{l}0.138 \\
0.138 \\
0.138 \\
0.138 \\
0.138 \\
0.138 \\
0.138 \\
0.138 \\
0.138 \\
0.138\end{array}$ & $\begin{array}{l}0.473 \\
0.573 \\
0.629 \\
0.587 \\
0.575 \\
0.610 \\
0.564 \\
0.616 \\
0.674 \\
0.581\end{array}$ & $\begin{array}{l}\text { Valid } \\
\text { Valid } \\
\text { Valid } \\
\text { Valid } \\
\text { Valid } \\
\text { Valid } \\
\text { Valid } \\
\text { Valid } \\
\text { Valid } \\
\text { Valid }\end{array}$ \\
\hline
\end{tabular}

Sumber: Data primer yang diolah SPSS v24

Berdasarkan data di atas, kesimpulan dari uji validitas ini dari 40 pernyataan, keseluruhan pernyataan dari tiap-tiap variabel dinyatakan valid. Hal ini dibuktikan dengan nilai corrected item-total correlation lebih besar dari t tabel $(0,138)$. Dapat disimpulkan bahwa butir-butir pernyataan dari masing-masing variabel dapat digunakan untuk mengukur dalam pengujian selanjutnya.

\section{b. Uji Reliabilitas}

Tabel 4.2

Data Uji Reliabilitas

\begin{tabular}{|c|c|c|}
\hline Variabel & Cronbach's Alpha & $\begin{array}{c}\text { Kategori Interval } \\
\text { Reliabilitas }\end{array}$ \\
\hline Kompensasi (X1) & 0,829 & Sangat Reliabel \\
\hline Motivasi (X2) & 0,822 & Sangat Reliabel \\
\hline Disiplin (X3) & 0,810 & Sangat Reliabel \\
\hline Kinerja Karyawan (Y) & 0,785 & Reliabel \\
\hline
\end{tabular}

Berdasarkan tabel di atas, dapat disimpulkan bahwa hasil uji reliabilitas dengan program SPSS v24 didapatkan untuk variabel kompensasi (X1) nilai Cronbach's Alpha 0,829 adalah sangat reliabel, sedangkan untuk variabel motivasi (X2) nilai Cronbach's Alpha 0,822 adalah sangat reliabel, untuk variabel disiplin(X3) nilai Cronbach's Alpha 0,810 adalah sangat reliabel dan variabel kinerja (Y) nilai Cronbach's Alpha 0,785 adalah sangat reliabel. Jadi keseluruhan pernyataan pada penelitian ini memiliki tingkat kehandalan yang baik dan dapat digunakan dalam analisis pada penelitian ini. 


\section{Uji Asumsi Klasik}

a. Uji Normalitas

\begin{tabular}{|c|c|c|c|c|c|}
\hline & \multicolumn{5}{|c|}{$\begin{array}{c}\text { Tabel } 4.3 \\
\text { Hasil Uji Normalitas Data } \\
\text { One-Sample Kolmogorov-Smirnov Test }\end{array}$} \\
\hline & & $\begin{array}{c}\text { KOMPENSASI } \\
(\mathrm{X} 1)\end{array}$ & $\begin{array}{l}\text { MOTIVASI } \\
(\mathrm{X} 2) \\
\end{array}$ & $\begin{array}{l}\text { DISIPLIN } \\
(\mathrm{X} 3)\end{array}$ & $\begin{array}{l}\text { KINERJA } \\
(Y)\end{array}$ \\
\hline $\mathrm{N}$ & & 209 & 209 & 209 & 209 \\
\hline \multirow{2}{*}{$\begin{array}{l}\text { Normal } \\
\text { Parameters }{ }^{a, b}\end{array}$} & Mean & 38,20 & 36,87 & 40,80 & 42,17 \\
\hline & $\begin{array}{l}\text { Std. } \\
\text { Deviation }\end{array}$ & 6,273 & 6,683 & 5,642 & 5,268 \\
\hline \multirow{3}{*}{$\begin{array}{l}\text { Most Extreme } \\
\text { Differences }\end{array}$} & Absolute & ,076 & ,101 & ,083 & , 101 \\
\hline & Positive & ,042 & ,072 &, 065 &, 069 \\
\hline & Negative &,- 076 &,- 101 &,- 083 &,- 101 \\
\hline \multicolumn{2}{|l|}{ Test Statistic } & ,076 & , 101 & ,083 & ,101 \\
\hline \multicolumn{2}{|c|}{ Asymp. Sig. (2-tailed) } &, $006^{c}$ &, $000^{c}$ &, $001^{c}$ &, $000^{\circ}$ \\
\hline \multicolumn{6}{|c|}{$\begin{array}{l}\text { a. Test distribution is Normal. } \\
\text { b. Calculated from data. } \\
\text { c. Lilliefors Significance Correction. }\end{array}$} \\
\hline
\end{tabular}

Berdasarkan tabel di atas, nilai Kolmogorov-Smirnov variabel Kompensasi $\left(\mathrm{X}_{1}\right)$ sebesar 0.076, variabel Motivasi $\left(\mathrm{X}_{2}\right)$ sebesar 0.101, variabel Disiplin (X3) 0.083 sedangkan variabel Kinerja (Y) sebesar 0.101 , berarti data residual terdistribusi normal.

b. Uji Heteroskedastisitas data

Tabel 4.4

Hasil Uji Heteroskedastisitas

\begin{tabular}{|c|c|c|c|c|c|c|}
\hline \multicolumn{7}{|c|}{ Coefficients $^{\mathbf{a}}$} \\
\hline & & \multicolumn{2}{|c|}{$\begin{array}{c}\text { Unstandardized } \\
\backslash \text { Coefficients }\end{array}$} & \multirow{2}{*}{$\begin{array}{c}\begin{array}{c}\text { Standardized } \\
\text { Coefficients }\end{array} \\
\text { Beta } \\
\end{array}$} & \multirow[b]{2}{*}{$\mathrm{t}$} & \multirow[b]{2}{*}{ Sig. } \\
\hline \multicolumn{2}{|c|}{ Model } & B & Std. Error & & & \\
\hline \multirow[t]{4}{*}{1} & (Constant) & 6.811 & 1.431 & & 4.761 & .000 \\
\hline & Kompensasi (X1) & .060 & .027 & .158 & 2.239 & .026 \\
\hline & Motivasi Kerja(X2) & .015 & .026 & .041 & .574 & .574 \\
\hline & Disiplin(X3) & .66 & .032 & .157 & 2.091 & .038 \\
\hline
\end{tabular}

a. Dependent Variable: RES 2

Sumber : Data diolah SPSS v24

Heterokedastisitas merupakan keadaan dimana seluruh residual atau error tidak memiliki varian yang sama untuk seluruh pengamatan atas variabel independen.

\section{c. Uji Multikolinearitas}

Tabel 4.5

Hasil Uji Multikolinearitas

\begin{tabular}{|c|c|c|c|c|c|c|c|c|}
\hline \multicolumn{9}{|c|}{ Coefficients $^{a}$} \\
\hline \multirow{2}{*}{\multicolumn{2}{|c|}{ Model }} & \multicolumn{2}{|c|}{$\begin{array}{l}\text { Unstandardized } \\
\text { Coefficients }\end{array}$} & \multirow{2}{*}{$\begin{array}{c}\text { Standardized } \\
\text { Coefficients } \\
\text { Beta }\end{array}$} & \multirow[b]{2}{*}{$\mathrm{t}$} & \multirow[b]{2}{*}{ Sig. } & \multicolumn{2}{|c|}{$\begin{array}{l}\text { Collinearity } \\
\text { Statistics }\end{array}$} \\
\hline & & B & Std. Error & & & & Tolerance & VIF \\
\hline 1 & (Constant) & 7,887 & 2,081 & & 3,791 & 000 & & \\
\hline & $\begin{array}{l}\text { KOMPENSASI } \\
(\mathrm{X} 1)\end{array}$ & ,294 & ,039 & ,350 & 7,528 &, 000 & ,918 & 1,089 \\
\hline & MOTIVASI (X2) & ,368 & ,038 & ,467 & 9,724 & ,000 & ,856 & 1,168 \\
\hline & DISIPLIN (X3) & ,233 & ,046 & ,249 & 5,059 &, 000 & ,816 & 1,225 \\
\hline
\end{tabular}

a. Dependent Variable: KINERJA (Y)

Sumber:Data diolah SPSS v24 
Dari data tabel di atas maka dapat disimpulkan dalam uji multikolonieritas ini adalah:

1) Jika dilihat dari hasil nilai toleransi pada variabel Kompensasi sebesar 0,918, variabel motivasi sebesar 0.856 dan variabel Disiplin sebesar 0,816 Maka dapat disimpulkan bahwa nilai dari masing-masing variabel lebih besar dari 0,10 , yang artinya tidak terjadi multikolonieritas terhadap data yang di uji.

2) Dan jika dilihat dari nilai VIF pada variabel Kompensasi sebesar 1.089, variabel motivasi sebesar 1.168 dan variabel lingkungan kerja sebesar 1.225. Maka dapat diambil kesimpulan bahwa nilai dari masing-masing variabel lebih kecil dari 10,00 yang artinya tidak terjadi multikolonieritas terhadap data yang di uji.

\section{Analisis Regresi}

Tabel 4.6

Uji Koefisien Determinasi Disiplin Terhadap Kinerja Karyawan Model Summary ${ }^{b}$

\begin{tabular}{|c|c|r|r|r|}
\hline Model & R & R Square & $\begin{array}{c}\text { Adjusted R } \\
\text { Square }\end{array}$ & $\begin{array}{c}\text { Std. Error of } \\
\text { the Estimate }\end{array}$ \\
\hline 1 & $.519^{\mathrm{a}}$ & .269 & .266 & 4.51373 \\
\hline
\end{tabular}

a. Predictors: (Constant), Disiplin (X3)

b. Dependent Variable: Kinerja (Y)

Sumber: Peneliti, Output SPSS v24 yang diolah, 2018

Dari tabel di atas didapat nilai R Square sebesar 0.269 yang menunjukkan bahwa variabel Y (Kinerja) dipengaruhi oleh variabel $\mathrm{X}_{3}$ (Disiplin) sebesar $26.9 \%$ dan sisanya sebesar $73.1 \%$ dipengaruhi oleh faktor-faktor lain yang tidak diteliti.

\section{Tabel 4.7}

Uji F Regresi Berganda Kompensasi, Motivasi dan Disiplin terhadap Kinerja

\begin{tabular}{|c|c|c|c|c|c|c|}
\hline \multicolumn{7}{|c|}{ Coefficients $^{\mathrm{a}}$} \\
\hline & \multirow{2}{*}{ Model } & \multicolumn{2}{|c|}{$\begin{array}{c}\text { Unstandardized } \\
\text { Coefficients }\end{array}$} & \multirow{2}{*}{$\begin{array}{c}\begin{array}{c}\text { Standardized } \\
\text { Coefficients }\end{array} \\
\text { Beta }\end{array}$} & \multirow{2}{*}{$\mathrm{t}$} & \multirow{2}{*}{ Sig. } \\
\hline & & B & $\begin{array}{l}\text { Std. } \\
\text { Error }\end{array}$ & & & \\
\hline \multirow{4}{*}{1} & (Constant) & 7.887 & 2.081 & & 3.791 & .000 \\
\hline & Kompensasi (X1) & .294 & .039 & .350 & 7.528 & .000 \\
\hline & Motivasi (X2) & .368 & .038 & .467 & 9.724 & .000 \\
\hline & Disiplin (X3) & .233 & .046 & .249 & 5.059 & .000 \\
\hline
\end{tabular}

a. Dependent Variable: Kinerja (Y)

Berdasarkan hasil output SPSS pada tabel diatas, maka dapat diidentifikasikan bahwa persamaan regresi sebagai berikut:

$$
\mathrm{Y}=7.887+0.294 \mathrm{X}_{1}+0.368 \mathrm{X}_{2}+0.233 \mathrm{X}_{3}
$$

Tabel 4.8

Uji Simultan (F) Kompensasi, Motivasi dan Disiplin Terhadap Kinerja ANOVA ${ }^{a}$

\begin{tabular}{|l|l|l|r|r|r|c|}
\hline \multicolumn{2}{|c|}{ Model } & $\begin{array}{l}\text { Sum of } \\
\text { Squares }\end{array}$ & \multicolumn{1}{c|}{ df } & $\begin{array}{c}\text { Mean } \\
\text { Square }\end{array}$ & F & Sig. \\
\hline \multirow{2}{*}{1} & Regression & 3485.017 & 3 & 1143.339 & 100.088 & $.000^{\mathrm{b}}$ \\
& Residual & 2341.782 & 205 & 11.423 & & \\
& Total & 5771.799 & 208 & & & \\
\hline
\end{tabular}

a. Dependent Variable: Kinerja (Y)

b. Predictors: (Constant), Disiplin (X3), Kompensasi (X1), Motivasi (X2)

Sumber: Peneliti, Output SPSS v24 yang diolah, 2018 
Dari tabel di atas, dapat diperoleh melalui hasil Statistical Product and Service Solutions (SPSS) versi 24 for Windows ini berarti, uji hipotesis secara simultan yaitu untuk menguji seberapa besar pengaruh secara bersama-sama variabel bebas terhadap variabel terikat digunakan uji F. Dari hasil perhitungan diperoleh nilai $F_{\text {hitung }}$ sebesar 100.144 dan signifikansi sebesar 0.000 . Jadi $F_{\text {hitung }}>F_{\text {tabel, }}(100.144>2.65)$ dan signifikansi lebih kecil dari 5\% $(0.000<0.05)$. Artinya bahwa secara bersama-sama variabel bebas yang terdiri dari variabel Kompensasi $\left(\mathrm{X}_{1}\right)$, Motivasi $\left(\mathrm{X}_{2}\right)$ dan Disiplin $\left(\mathrm{X}_{3}\right)$ berpengaruh positif dan signifikan terhadap variabel Kinerja $(\mathrm{Y})$.

Tabel 4.9

Hasil Uji Determinasi

Model Summary ${ }^{b}$

\begin{tabular}{|c|r|r|r|r|}
\hline Model & R & R Square & $\begin{array}{c}\text { Adjusted R } \\
\text { Square }\end{array}$ & $\begin{array}{c}\text { Std. Error of } \\
\text { the Estimate }\end{array}$ \\
\hline 1 & $.777^{\mathrm{a}}$ & .594 & .588 & 3.380 \\
\hline
\end{tabular}

a. Predictors: (Constant), Disiplin (X3), Kompensasi

(X1), Motivasi (X2)

b. Dependent Variable: Kinerja (Y)

Dari tabel di atas didapat nilai Adjusted R Square sebesar 0.588 yang menunjukkan bahwa variabel $\mathrm{Y}$ (Kinerja) dipengaruhi oleh variabel $\mathrm{X}_{1}$ (Kompensasi), variabel $\mathrm{X}_{2}$ (Motivasi) dan variabel $\mathrm{X}_{3}$ (Disiplin) sebesar $58.8 \%$ dan sisanya sebesar $41.2 \%$ dipengaruhi oleh faktor-faktor lain yang tidak diteliti.

\section{PENUTUP}

\section{A. Kesimpulan}

1. Kompensasi ( X1 ) berpengaruh positif dan signifikan terhadap Kinerja pada karyawan ( Y ) PT. Sunindo Adi Persada. Hal ini dapat dibuktikan dari nilai regresi sederhana $\mathrm{Y}=26,143+0,420 \mathrm{X}$, Nilai $\mathrm{t}$ hitung 8,301 $>\mathrm{t}$ tabel 1,971 dengan signifikan $0,000<0,05$, Nilai korelasi sebesar 0,500 , besarnya kontribusi kompensasi terhadap kinerja karyawan sebesar $50 \%$.

2. Motivasi (X ) berpengaruh positif dan signifikan terhadap Kinerja pada karyawan (Y) PT. Sunindo Adi Persada. Hal ini dapat dibuktikan dari nilai regresi sederhana $\mathrm{Y}=24,122+0,490 \mathrm{X}$, Nilai $\mathrm{t}$ hitung 11,401 $>\mathrm{t}$ tabel 1,971 dengan signifikan $0,000<0,05$, Nilai korelasi sebesar 0,621 , besarnya kontribusi motivasi terhadap kinerja karyawan sebesar $62,1 \%$.

3. Disiplin ( X3 ) berpengaruh positif dan signifikan terhadap Kinerja pada karyawan (Y) PT. Sunindo Adi Persada. Hal ini dapat dibuktikan dari nilai regresi sederhana $\mathrm{Y}=22,405+0,485 \mathrm{X}$, Nilai $\mathrm{t}$ hitung 8,735 $>\mathrm{t}$ tabel 1,971 dengan signifikan $0,000<0,05$, Nilai korelasi sebesar 0,519 , besarnya kontribusi disiplin terhadap kinerja karyawan sebesar 51,9\%.

4. Kompensasi ( X1 ), Motivasi ( X2) dan Disiplin ( X3 ) secara bersama-sama berpengaruh positif dan signifikan terhadap Kinerja pada karyawan ( Y ) PT. Sunindo Adi Persada. Hal ini dapat dibuktikan dari nilai regresi berganda yang diperoleh yaitu $\mathrm{Y}=7,887+0.294 \mathrm{X}_{1}+0.368 \mathrm{X}_{2}+0,233 \mathrm{X}_{3}$, Nilai $\mathrm{F}$ hitung $100,144>\mathrm{F}$ tabel 2,41 dengan siginifikan $0,000<0,05$, besarnya kontribusi Kompensasi $\left(\mathrm{X}_{1}\right)$ Motivasi $\left(\mathrm{X}_{2}\right)$ dan Disiplin $\left(\mathrm{X}_{3}\right)$ terhadap variabel kinerja karyawan $(\mathrm{Y})$ sebesar 58,8\%.

\section{B. Saran}

1. Seharusnya kepada pihak manajemen untuk terus mengupayakan dan meningkatkan Asuransi kesehatan kepada semua karyawan guna meningkatkan kinerja pada karyawan. 
2. Seharusnya kepada pihak manajemen untuk memberikan kesempatan kepada semua karyawan untuk bekerja pada pekerjaan yang diminati dan sesuai dengan kemampuan.

3. Seharusnya kepada pihak manajemen terlebih kepada para pimpinan agar dapat memberikan teladan kepada semua karyawan dalam hal jam masuk dan pulang agar dilaksanakan sesuai dengan aturan perusahaan.

Seharusnya kepada pihak manajemen untuk memberikan pelatihan kepada semua karyawan agar dapat bekerja lebih profesional.

\section{DAFTAR PUSTAKA}

A.A.Anwar Prabu Mangkunegara. 2011. Manajemen Sumber Daya Manusia Perusahaan. PT. Remaja Rosda Karya, Bandung.

Alex S .Nitisemito, 2010, Manajemen Personalia, Ghalia Indonesia, Jakarta.

Algifari. 2007. Analisis: Teori dan Kasus Solusi. BPFE UGM. Yogyakarta.

Arikunto, Suharsimi.2011. Prosedur Penelitian, Suatu Pendekatan Praktik, Edisi Revisi 2011 Jakarta, Rineka Cipta.

Bohlander, George., and Snell, Scott. (2010). Principles of Human Resource. Management, 15th ed. Mason, $\mathrm{OH}$ : South Western - Cengage Learning.

Flippo,Edwin B. 2010,Manajenen Personalia.PT Glora Aksara Pratama,Jakarta.

Ghozali, Imam. (2011). Aplikasi Analisis Multivariate Dengan Program IBM SPSS 19 (edisi kelima.)Semarang: Universitas Diponegoro.

Hani, T. Handoko. 2013. Manajemen Personalia dan Sumber Daya Manusia. BPFEYogyakarta. Yogyakarta.

Harlie, M. 2010. Pengaruh Disiplin Kerja, Motivasi dan Pengembangan Karier Terhadap Kinerja Pegawai Negeri Sipil Pada Pemerintah Kabupaten Tabalong di Tanjung Kalimantan Selatan. Jurnal Manajemen dan Akuntansi 11 (2): 10-23.

Hasibuan, Malayu. 2011. Manajemen Dasar, Pengertian, Dan Masalah. Jakarta: PT Bumi Aksara.

Herman, Sofyandi. 2009. Manajemen Sumber Daya Manusia.Yagyakarta. Graha Ilmu.

H. Simamora. 2010. Manajemen Sumber Daya Manusia. Yogyakarta : STIE YKPN

Malayu S.P Hasibuan. (2012). Manajemen Sumber Daya Manusia. Jakarta: PT. Bumi Aksara.

Manullang,2010.Manajemen Sumber Daya Manusia.Salemba 4 Jakarta.

Marwansyah. 2010. Manajemen sumber daya manusia. Alfabeta:Bandung

Mondy R Wayne. 2011. Manajemen Sumber Daya Manusia. Jakarta: Erlangga.

Muhammad Luthil Hakim.(2010),Teori Belajar dan Pembelajaran-Konsep Belajar dan Pembelajaran.

Munandar, Ashar Sunyoto. 2009. Psikologi Industri dan Organisasi. Universitas Indonesia, Jakarta.

R.Terry, George dan Leslie W.Rue. Dasar-Dasar Manajemen. (Jakarta: Bumi Aksara, 2010)

Robbins \& Coulter. 2012. Manajemen. Jakarta : Indeks.

Siagian, Sodang P. (2014). Manajemen sumber daya manusia. Jakarta: Bumi Aksara.

Stephen.P Robbins- Timothy A Judge.2012. Perilaku Organisasi,Jakarta : salemba empat.

Sugiyono, 2009, Metode Penelitian Kuantitatif, Kualitatif dan $R \& D$, Bandung : Alfabeta.

Sunarsi, D. (2019). Pengaruh Kompensasi, Komunikasi Dan Stress Kerja Terhadap Prestasi Kerja Karyawan Pada PT Catur Putra Jaya Kota Depok-Jawa Barat. Jimf (Jurnal Ilmiah Manajemen Forkamma), 1(2).

Veithzal Rivai dan Ella Sagala,2013.Manajemen Sumber Daya Manusia Untuk Perusahaan, Rajawali Pers 